\section{PLO6 - MATHEMATICAL MODELLING, A LUXURY OR A NECESSITY IN STD CONTROL?}

\author{
Monday, July 15, 2019 2:55 PM - 3:30 PM
}

\section{PL06.1 MATHEMATICAL MODELLING, A LUXURY OR A NECESSITY IN STD CONTROL?}

Geoff Garnett*. Bill and Melinda Gates Foundation, Seattle, USA

10.1136/sextrans-2019-sti.9

Mathematical models of sexually transmitted disease (STD) aim to represent sexual contact networks, pathogen characteristics, and intervention activities, helping understand and quantify STD epidemics and their control. Models are, unfortunately, necessary because non-linear infectious disease dynamics combined with many interacting variables undermines intuitive understanding. It is hoped that rational decision makers will include a range of evidence, including the finding of models, in funding, planning, implementing, and evaluating STD interventions and programs. The level of detailed required for informative models that can lead to better decisions, and how models can best be included in the international, national, and local public health ecosystem are areas for attention. Questions to consider are: 1) The pros and cons of focusing resources on sub-groups within a population. This is influenced by the biology and behavior associated with the STD, along with structural context. 2) How to ensure successful implementation of interventions? Here simple cascades are being used to identify gaps in treatment and prevention. 3) What is the relative value of developing, introducing and scaling the use of specific testing, treatment and prevention products in STD programs? The epidemiological context and coverage of other interventions have profound implications here. 4) How do we design a surveillance system that provides timely and actionable data on STD epidemiology? Here again the epidemiological context matters. The history of modeling STDs provides many examples that address such questions, and models are currently influencing policy, particularly in HIV programs. However, the development and validation of models in STD epidemiology has been hampered by our inability to directly measure the sexual network via which STDs spread. Recent efforts to evaluate model performance, and advances in pathogen sequencing and phylogenetic analysis, provide avenues to improve the validity and utility of STD models as their use becomes more systematic.

Disclosure No significant relationships.
PLO7 - GLOBAL TRENDS IN HIV IN THE ERA OF COMBINATION PREVENTION - WHAT PROGRESS HAVE WE MADE TOWARDS ELIMINATION?

Tuesday, July 16, 2019 8:15 AM - 8:50 AM

\section{PL07.1 GLOBAL TRENDS IN HIV IN THE ERA OF COMBINATION PREVENTION - WHAT PROGRESS HAVE WE MADE TOWARDS ELIMINATION?}

Wafaa El-Sadr*. Columbia University, New York, USA

10.1136/sextrans-2019-sti.10

The global HIV response has had notable effects on the trajectory of the epidemic. Dramatic declines in morbidity and mortality have been noted in association with the scale-up of effective antiretroviral therapy (ART). Additionally, the number of new HIV infections has decreased to historical lows. However, only about half of the persons living with HIV have accessed ART and more than one million new HIV infections were reported in 2017. Evidence indicates that there is unlikely to be a single magic bullet for prevention of HIV transmission. Rather, combination HIV prevention strategies have been posited as the way to achieve the goal of decreasing the number of new infections to 500,000 by 2020 , with a focus on both HIV negative and HIV positive individuals. A mix of behavioral, biomedical and structural HIV prevention interventions are likely to be needed. Several large studies have been completed examining the effect of combination prevention strategies on HIV with mixed results at a community level. At the same time, the findings from recently conducted Population-based HIV Impact Assessment (PHIA) surveys in several sub Saharan African countries have demonstrated some impressive, but variable progress in controlling the epidemic. Both of these efforts have shed light on the gaps in the HIV response. This plenary talk will provide background information on the status of the global HIV epidemic, progress to date, gaps in the response, and ways in which combination prevention approaches can show the path towards epidemic control.

\section{PL08 - \#METOO MOVEMENT, SYSTEMS OF POWER AND SEXUAL HEALTH AND WELLBEING: THE WIDENING OF THE \#METOO MOVEMENT}

Tuesday, July 16, 2019 8:50 AM - 10:00 AM

\section{PL08.1 \#METOO MOVEMENT, SYSTEMS OF POWER AND SEXUAL HEALTH AND WELLBEING: THE WIDENING OF THE \#METOO MOVEMENT}

${ }^{1}$ Irin Carmon*, ${ }^{2}$ Rebecca Thurston*. ${ }^{1}$ New York Magazine and CNN Contributor, New York, USA; ${ }^{2}$ University of Pittsburgh, Pittsburgh, USA

10.1136/sextrans-2019-sti.11

The Plenary Panel '\#MeToo Movement, Systems of Power and Sexual Health and Wellbeing: The Widening of the 